\title{
INCLUSIÓN DE LA NIÑEZ EN LAS COMISIONES DE LA VERDAD: GUATEMALA Y ARGENTINA
}

Mónica Mendoza Molina

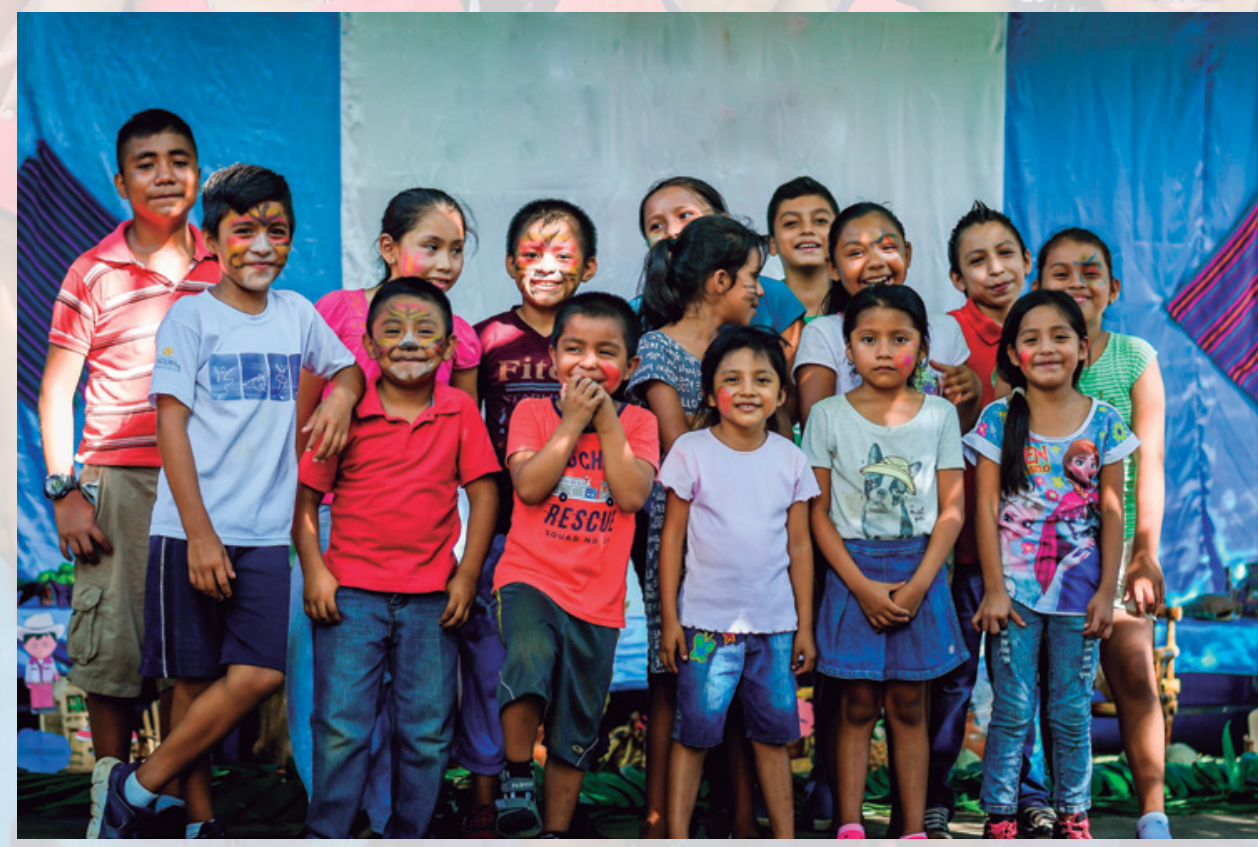





\title{
INCLUSIÓN DE LA NIÑEZ EN LAS COMISIONES DE LA VERDAD: GUATEMALA Y ARGENTINA
}

\author{
Mónica Mendoza Molina \\ Universidad NaCiOnal de Colombia
}

\section{Resumen}

El presente documento es resultado de un ejercicio de investigación cualitativa con enfoque hermenéutico documental, con el que se buscó analizarlas formasen las que abordaba la niñez en las Comisiones de la Verdad de Argentina y Guatemala, después de la dictadura militar y el conflicto armado interno, respectivamente. Se identificaron elementos comunes o diferenciados y se analizó el rol de la normativa internacional en la materia. Para ello, se examinaron los informes emitidos por las comisiones, denominados en ambos casos Nunca más. En general, los casos son muy diferentes, dado que Argentina solo trató en sus investigaciones el delito de desaparición forzada, mientras que Guatemala incluyó muchas otras vulneraciones a los derechos humanos, lo cual repercute de manera directa en el abordaje de la niñez. En ambos países, niños, niñas, adolescentes y jóvenes (NNAJ) fueron usados como "botín de guerra", para "acabar con la semilla" e instrumento para infligir dolor a los padres. Es posible identificar en común el delito de desaparición forzada y robo de identidad, que Argentina ha venido enfrentando con decisión por medio de un arduo trabajo de más de cuatro décadas, mientras que Guatemala presenta avances escasos y esfuerzos limitados, pese a que esa fue una de las recomendaciones de la Comisión para el Esclarecimiento Histórico. El papel que desempeña la normativa internacional, en particular la Convención sobre los derechos del niño (CDN), es determinante para la comprensión de las afectaciones diferenciales de la niñez en situaciones de conflicto y vulneraciones graves a los derechos humanos. Además, el seguimiento de entes como el Comité de los Derechos del Niño a estos casos es relevante, pero no determinante. Para próximos trabajos sería pertinente indagar por el activismo político que los NNAJ robados de ayer desempeñan hoy día como adultos.

Palabras clave: niñez, comisiones de la verdad, derechos humanos, Argentina, Guatemala.

La autora: magíster en Desarrollo Educativo y Social, doctoranda en Estudios políticos y relaciones internacionales de la Universidad Nacional de Colombia. ORCID: 111156. Correo electrónico: mamendozam@unal.edu.co

Recibido: 11 de junio de 2021; evaluado: 20 de agosto de 2021; aceptado: 7 de octubre de 2021. 


\title{
INCLUSION OF CHILDREN IN TRUTH COMMISSIONS: GUATEMALA AND ARGENTINA
}

\author{
Mónica Mendoza Molina \\ Universidad NaCional de Colombia
}

\begin{abstract}
This document is the result of a qualitative research with a documentary hermeneutical approach, which sought to determine the ways in which children were included in the truth commissions developed in Argentina and Guatemala - after the military dictatorship and the armed conflict, respectively-by identifying common or differential elements and analyzing the role of related international regulations. To this end, the commissions' reports, called in both cases "Never Again," were analyzed. In general, the cases are very different; Argentina only included the crime of forced disappearance in its investigations, while Guatemala included many other human rights violations, which have a direct impact on approaching childhood. In both cases, children and adolescents were used as "spoils of war," as a message to stop "the bad seed," and as an instrument to inflict pain on parents. It is possible to identify the common crimes of forced disappearance and identity theft, which Argentina has been confronting with determination and hard work for more than four decades, while Guatemala shows little progress and limited efforts, despite this being one of the recommendations of the Commission for Historical Clarification. The role played by international regulations, particularly the Convention on the Rights of the Child, is decisive for understanding the differential affectations of children in armed conflicts and serious violations of human rights. Likewise, the monitoring carried out by entities like the Committee on the Rights of the Child is relevant in these cases, but not decisive. For future works, it would be pertinent to inquire about the role of political activism that stolen children and adolescents perform today.
\end{abstract}

Keywords: childhood, truth commissions, human rights, Argentina, Guatemala.

About the author: MA in Educational and Social Development, PhD candidate in Political Studies and International Relations, Universidad Nacional de Colombia. ORCID: 111156. E-mail: mamendozam@ unal.edu.co

Received: June 11, 2021; evaluated: August 20, 2021; accepted: October 7, 2021. 


\title{
INCLUSÃO DA INFÂNCIA NAS COMISSÕES DA VERDADE: ARGENTINA E GUATEMALA
}

\author{
Mónica Mendoza Molina \\ Universidad NaCiOnal de Colombia
}

\section{Resumo}

Este documento é resultado de um exercício de pesquisa qualitativa com abordagem hermenêutica documental, com o qual se pretendeu determinar as formas como a infância foi incluída nas comissões da verdade desenvolvidas na Argentina e na Guatemala, depois da ditadura militar e do conflito armado interno, respectivamente. Foram identificados elementos comuns ou diferenciados e analisado o papel da legislação internacional na matéria. Para isso, foram examinados os relatórios emitidos pelas comissões, denominados em ambos os casos "Nunca mais". Em geral, os casos são muito diferentes, tendo em vista que a Argentina somente tratou em suas pesquisas do delito de desaparecimento forçado, enquanto a Guatemala incluiu muitas outras violações dos direitos humanos, o que repercute de maneira direta na abordagem da infância. Nos dois países, crianças, adolescentes e jovens foram usados como espólio de guerra para "acabar com a semente" e instrumento para infringir dor aos pais. É possível identificar em comum o delito de desaparecimento forçado e o roubo de identidade que a Argentina enfrentou com a decisão por meio de um trabalho duro de mais de quatro décadas, enquanto a Guatemala apresenta pouco progresso e esforços limitados, embora essa tenha sido uma das recomendações da Comissão para o Esclarecimento Histórico. O papel que a legislação internacional desempenha, em particular a Convenção sobre os Direitos da Criança, é determinante para compreender as afetações diferenciais da infância em situações de conflito e violações graves dos direitos humanos. Além disso, o seguimento de entidades como a Comissão dos Direitos da Criança a esses casos é relevante, mas não determinante. Para futuros trabalhos, seria pertinente questionar o ativismo político que crianças, adolescentes e jovens roubados de ontem desempenham hoje como adultos.

Palavras-chave: infância, comissões da verdade, direitos humanos, Argentina, Guatemala.

A autora: mestra em Desenvolvimento Educativo e Social, doutorando em Estudos políticos e relações internacionais da Universidad Nacional de Colombia. ORCID: 111156. Correio eletrônico: mamendozam@ unal.edu.co

Recebido: 11 de junho de 2021; avaliado: 20 de agosto de 2021; aceito: 7 de outubro de 2021. 


\section{Introducción}

El presente texto tiene por objetivo analizar las formas en las que fue abordada la niñez en las Comisiones de la Verdad de Guatemala y de Argentina. Si bien los dos casos son muy diferentes, convergen en la investigación y la denuncia sobre la práctica de secuestro de NNAJ y el consecuente robo de identidad. Cabe señalar que, pese a los avances normativos y al reconocimiento que se hace de los NNAJ como sujetos con capacidad de agencia y con necesidades de especial protección, las vulneraciones a sus derechos se mantienen y se exacerban en contextos de violencias extremas.

Las Comisiones de la Verdad son diversas y dependen fundamentalmente del contexto político en el que se instalan, pero mantienen una serie de características comunes: el tiempo de su mandato es limitado, estudian las violaciones graves a los derechos humanos, están conformadas por académicos o miembros de "buena reputación", no implican una sanción penal para los responsables de la violencia, producen "una verdad histórica", otorgan fundamental reconocimiento a las víctimas y se conforman como una opción de salida a la violencia. Estas características se han posicionado gracias a un proceso de aprendizaje internacional.

Para Lefranc, quizás el aspecto de mayor controversia se relaciona con el hecho de que dichas comisiones no actúan como órganos judiciales y, por tanto, pueden propiciar impunidad bajo la figura de amnistías que, según el país, pueden ser generales, restrictivas o condicionales. En general, estas dejan una sensación de inconformismo en la mayoría de las víctimas, aunque en ocasiones son la única salida a la crisis.

El fin de un conflicto, un enfrentamiento violento o un régimen represor, rara vez se corresponde con la derrota de una de las partes; más bien, se ubica en el campo de la negociación y el disenso (acuerdos mínimos de coexistencia), lo que suele resultar cuestionable, sobre todo a la luz de los crímenes de lesa humanidad. Así pues, "los responsables de la violencia de Estado detentan a menudo un poder suficiente como para imponer a los gobiernos democráticos la renuncia a los procesamientos judiciales" y se instauran, en cambio, un modelo de escarnio público que rara vez

Sandrine Lefranc, “¿Cómo acabar con el desacuerdo? Las Comisiones de la Verdad y Reconciliación como lugar de reconstrucción disensual de la historia" en Memorias en conflicto, ed. J. B. Raynald Belay (Lima: Institut français d'études andines, Instituto de Estudios Peruanos, Embajada de Francia en el Perú, Red para el Desarrollo de las Ciencias Sociales en el Perú, 2004), 207. 
afecta sus privilegios. En el mismo sentido, aunque se pretenda la construcción de una verdad imparcial, esta no necesariamente representa los intereses de las víctimas y puede subordinar el interés de los derechos humanos al interés de la democracia.

Los aportes de las Comisiones de la Verdad se conforman entonces como "paliativos simbólicos", ante la ausencia de justica. Sus mayores logros consisten en establecer hechos vinculados a la violación grave de los derechos humanos y permitir hablar a las víctimas, para producir un relato histórico en el que ellas son reconocidas y reparadas material o simbólicamente, en un escenario que se aleja de la justiciasanción a los verdugos. La consideración de los testimonios de las víctimas, por un lado, y la "confesión" de los victimarios, por otro, llevan a construir una verdad que puede resultar factual (hechos), personal (testimonio), social (debate) y restauradora (reconocimiento público), pero que, se reitera, no necesariamente representa a las víctimas, pues hay violencias que no pueden perdonarse y que no se desgastan en el tiempo.

Después de la dictadura militar, en Argentina se conformó la Comisión Nacional sobre la Desaparición de Personas, que se ocupó de investigar y documentar prácticas, hechos y procedimientos, ocurridos alrededor de las desapariciones durante el período conocido como Proceso de reorganización nacional, que tuvo lugar entre 1976 y 1983. Pese a que solo se abordó el delito de desaparición, parte del informe Nunca más se dedicó al abordaje de la niñez en ese escenario, en particular en los Capítulos I y II, apartados "Acción represiva (secuestro)" y "Víctimas (niños desaparecidos y embarazadas, y adolescentes). De acuerdo con las cifras oficiales, se estima que "500 bebés, niñas y niños, fueron separados de sus familias y apropiados bajo otra identidad". ${ }^{2}$

En Guatemala se adelantaron dos iniciativas para el esclarecimiento de la verdad: el Proyecto de recuperación de la memoria histórica (Remhi), liderado por la Iglesia católica, y la Comisión para el Esclarecimiento Histórico (CEH). El objetivo del primero era dar insumos a la $\mathrm{CEH}$, a partir de un trabajo de investigación eficaz con enfoque multicultural y multilingüe.

Como resultado de estas investigaciones, que recogieron más de 5000 testimonios, se emitió el informe Guatemala: nunca más. En su Tomo I, Capítulo 2, denominado

2 República Argentina, Ministerio de Relaciones Exteriores, Comercio Internacional y Culto, "Ayúdanos a encontrarte", https://www.cancilleria.gob.ar/es/encontrarte (acceso noviembre 5, 2021). 
"La destrucción de la semilla", aborda el asunto de la niñez. Por su parte, la CEH, se ocupó de investigar todo tipo de violaciones a los derechos humanos ocurridas en el marco del conflicto armado interno que experimentó este país entre 1962 y 1996; el asunto de la niñez tratado con profundidad dentro del informe Memoria del silencio, que le dedica un capítulo exclusivo. De acuerdo con las cifras allí reportadas, del $38 \%$ de las víctimas registradas (del $62 \%$ restante no se pudo determinar la edad ni el sexo), el $18 \%$ eran niños y niñas, el $79 \%$ adultos y el $3 \%$ ancianos. ${ }^{3}$

\section{Problema socio-jurídico analizado}

El reconocimiento de la niñez como actor fundamental en los conflictos armados internos o en las dictaduras no es definitivo y, si bien se ha documentado bastante la victimización de la niñez en estos escenarios, no siempre se ha implementado un enfoque diferencial o interseccional que la abarque desde diferentes aristas, para comprender sus afectaciones particulares por edad, género, pertenencia étnica o diversidad funcional; ello favorecería los procesos de verdad, justicia y reparación, y aportaría a la superación del análisis binario en torno a las categorías víctima-victimario.

Conforme con lo documentado por Unicef, ${ }^{4}$ la inclusión de la niñez en las Comisiones de la Verdad ha evolucionado, de manera que, durante la década de 1980 y principios de la de 1990, las comisiones de Chile, Salvador y Haití apenas consignaron algunos casos de violaciones contra NNAJ, pues mantuvieron un

3 República de Guatemala, Comisión para el Esclarecimiento Histórico, Guatemala: memoria del silencio (Ciudad de Guatemala: Oficina de Servicios para Proyectos de las Naciones Unidas, 1999), 323.

4 Unicef, Children and Truh Commissions (Florencia: Autor, 2010), X.

5 En 2003 en Chile, se creó la Comisión Nacional sobre Prisión Política y Tortura que tenía por mandato, determinar quiénes fueron las personas que sufrieron privación de libertad y torturas por razones políticas, por parte de agentes del Estado o personas a su servicio, durante la dictadura comprendida entre 1973 y 1990; en el año 2004 se emitió un primer informe (Valech I) y uno nuevo en el año 2011 (Valech II) sobre los casos de personas detenidas/ desaparecidas y ejecutadas políticas. República de Chile, Comisión Nacional sobre Prisión Política y Tortura, Informe de la comisión nacional sobre prisión política y tortura (Santiago: Ministerio del Interior, 2004), 21.

En El Salvador, se creó la Comisión de la Verdad como uno de los resultados del Tratado de Paz, firmado en el año 1992, después de la guerra comprendida entre 1980 y 1991. Dicha comisión tenía por mandato, investigar los graves hechos de violencia ocurridos en este periodo, así como esclarecer las violaciones a los derechos humanos; los resultados de las investigaciones están contenidos en el informe denominado "De la locura a la esperanza: la guerra de 12 años en El Salvador". Comisión de la Verdad para El Salvador, De la locura a la esperanza: la guerra de 12 años en El Salvador (San Salvador: Organización de las Naciones Unidas, 1993), 9.

Por su parte, en Haití se creó en 1995 la Comisión Nacional de Verdad y Justicia, emitiendo su informe en el año 1996. Durante el proceso, se recogieron testimonios de 5500 testigos, sobre aproximadamente 8600 víctimas. Priscilla Hayner, "Comisiones de la verdad: resumen esquemático", International Review 
marcado énfasis en los adultos. Se exceptúa Argentina, en donde se otorga especial importancia al fenómeno de niños robados o secuestrados.

Por su parte, a mediados de 1990 y principios de 2000, las Comisiones de Guatemala y Sudáfrica ${ }^{6}$ investigaron y reportaron un número mucho mayor de NNAJ víctimas que, en Guatemala pertenecían en su mayoría al pueblo maya. En Sudáfrica se consideró la participación directa de NNAJ en la Comisión por medio de sus testimonios, pero luego se determinó que el impacto emocional podría ser perjudicial, por lo que se implementaron técnicas como grupos focales o actividades artísticas para darles voz.

En cuanto a las Comisiones de Perú y Timor Oriental, ${ }^{7}$ se construyó un capítulo sobre las violaciones a los derechos de NNAJ, y la Comisión de Sierra Leona ${ }^{8}$ fue la primera en mencionar de manera explícita en su mandato el asunto de NNAJ y de los graves impactos que provocan los conflictos armados en esta población. ${ }^{9}$

La promulgación de la CDN, en 1989, marcó un derrotero en materia de infancia y, por tanto, influyó también en el abordaje de este asunto particular en las Comisiones

of the Red Cross, núm. 862 (2006): 16, https://www.icrc.org/es/doc/assets/files/other/irrc_862_hayner.pdf (acceso noviembre 5, 2021).

$6 \quad$ La Comisión de la Verdad y la Reconciliación de Sudáfrica surgió en el marco del tránsito del régimen de apartheid al sistema democrático, emitió su informe en el año 1998 y fue reconocida por recomendar enjuiciamientos o amnistías, potestades que no ostentan otras Comisiones de la Verdad. En ese sentido, su mandato consistía tanto en esclarecer violaciones a los derechos humanos, como "ejercer un tipo de justicia que no pusiera en peligro los acuerdos obtenidos entre las principales fuerzas políticas que dieron fin al apartheid". Juanita Andrea Millán Hernández, "Comisiones de la Verdad y posibles aprendizajes para el caso colombiano", Papel Politico 20, núm. 2 (2015): 439, http://www.scielo.org.co/pdf/papel/v20n2/v20n2a06. pdf (acceso noviembre 5, 2021).

7 En Perú, la Comisión de la Verdad y Reconciliación se creó en 2001 con "la finalidad de esclarecer la naturaleza del proceso y los hechos del conflicto armado interno que vivió el país, así como de determinar las responsabilidades derivadas de las múltiples violaciones de los derechos fundamentales ocurridas en aquellos años", este conflicto armado tuvo lugar entre 1980 y 2000 y se calcula, que aproximadamente 69280 personas perdieron la vida en consecuencia. República del Perú, Comisión de la Verdad y la Reconciliación, "Informe final", https://www.cverdad.org.pe/ifinal/ (acceso noviembre 5, 2021).

Por su parte, en Timor Oriental la Comisión de la Verdad se creó en 2002 para investigar los hechos de violencia ocurridos durante el periodo de independencia de Indonesia, emitiendo su informe en el año 2005, construido con la información recogida mediante de audiencias públicas regionales y nacionales.

8 En 1999 se firmó en Sierra Leona un tratado de paz para dar solución a un conflicto armado interno que tuvo lugar entre 1991 y 2002; en dicho tratado se estableció una Comisión de la Verdad y la Reconciliación que tenía como mandato abordar la impunidad, revelar la verdad y permitir que víctimas y perpetradores contaran su verdad. El informe fue presentado en 2004 y allí se establecieron más de 16 categorías específicas de violaciones, reportando 40242 en total. Centro Internacional para la Justicia Transicional [ICTJ], "La comisión de la verdad y la reconciliación de Sierra Leona", https:/www.ictj.org/sites/default/files/subsites/ challenging-conventional-truth-commissions-peace/sierra_leone_es.html \#01/1 (acceso octubre 11, 2021).

9 Unicef, Children, X. 
de la Verdad que tuvieron lugar con posterioridad, al incluir las voces de NNAJ su participación en la reconstrucción de la memoria histórica y la verdad, con el objetivo de superar las particulares situaciones de conflicto de cada país mediante el reconocimiento de las violaciones a los derechos humanos y del rol de las víctimas y los perpetradores en dichos escenarios.

Para el momento en el que tuvo lugar el proceso de reconstrucción de memoria y verdad en Argentina, con la Comisión Nacional sobre la Desaparición de Personas (Conadep), no se había promulgado la CDN, pero aun así se incluyó el asunto de la niñez, específicamente en relación con el robo de bebés o desaparición de NNAJ; Guatemala, por su parte, trató de manera detallada el tema de la niñez en su proceso de construcción de verdad y en el informe que de allí derivó.

Como se expondrá, la práctica de robo de identidad asociada a la desaparición de NNAJ fue común en ambos casos. Si bien se denunció y se determinó la necesidad de búsqueda y del restablecimiento a las familias biológicas, podrá observarse que, en Argentina, se ha tratado de un ejercicio de perseverancia transgeneracional, liderado por la organización Abuelas de Plaza de Mayo, cuyo empeño ha ofrecido resultados tanto en términos de la recuperación de nietos como de reivindicación política. No tanto así en Guatemala, pese a que una de las recomendaciones de la CEH fue la conformación de la Comisión nacional para la búsqueda de niños desaparecidos, así como "adoptar la legislación adecuada para la implementación de su mandato y facilitar los medios técnicos y científicos necesarios para la documentación y búsqueda de la niñez desaparecida, adoptada ilegalmente o separada ilegalmente de su familia". ${ }^{10}$ La ausencia de resultados en ese campo ha sido duramente cuestionada por organismos como el Comité de los Derechos del Niño, que señalan indiferencia del Gobierno para implementar políticas reales de búsqueda y hallazgo de NNAJ desparecidos en el marco del conflicto armado.

El papel de la norma internacional sobre asuntos de niñez y de conflictos armados resulta fundamental en los procesos de verdad y memoria, pues afecta en la forma de aproximarse al tema y a las disposiciones y recomendaciones que se proponen. Las disposiciones más relevantes se recogen en la CDN, la Convención sobre los derechos humanos y el derecho internacional humanitario (DIH).

10 Comisión Interamericana de Derechos Humanos, "Justicia e inclusión social: los desafíos de la democracia en Guatemala", http://www.cidh.org/countryrep/guatemala2003sp/capitulo6.htm (acceso noviembre 5, 2021). 
La CDN reconoce como niño a todo individuo entre 0 meses y 18 años cumplidos, aunque dentro de este rango se reconocen grupos específicos como la primera infancia, la infancia, la adolescencia y la juventud. La niñez ha sido asumida como el período en el que el ser humano debe formarse y crecer en ambientes propicios que faciliten su adecuado desarrollo. Si bien a escala internacional se define la edad de 18 años para delimitar este período, cada país puede definir la suya, de acuerdo con particularidades sociales, culturales y étnicas. Así, en Guatemala, por ejemplo, en varias comunidades mayas es común que los jóvenes se casen a partir de los 14 años y adquirieran obligaciones y facultades de adultos.

Según lo señalado por la CDN, las Comisiones de la Verdad deberían considerar en sus procedimientos, su implementación y sus recomendaciones, los principios de interés superior del niño y no discriminación, así como los derechos a nombre, nacionalidad, preservación de la identidad, no separación de padres y madres, reunificación familiar, libertad de expresión y conciencia, protección, refugio, recuperación y reintegración.

Con posterioridad a las Comisiones de la Verdad de Argentina y Guatemala, en el año 2002, se añadió el Protocolo Facultativo en la CDN alusivo a la participación directa de NNAJ en las hostilidades propias de los conflictos armados. Estableció que los Estados parte deberán hacer todos sus esfuerzos para que ninguna persona menor de 18 años participe en dichas actividades. Aunque este Protocolo es ulterior a los casos que nos ocupan, la práctica de reclutamiento de NNAJ en Guatemala fue muy común, tanto por parte de las guerrillas como del Estado, con su vinculación a las patrullas de autodefensa comunitaria (PAC), reconocidas como fuerzas paramilitares controladas y adiestradas por el Ejército, con el objetivo de:

[...] organizar a la población civil contra los movimientos guerrilleros y lograr un control físico y psicológico sobre la población. Es así como el fenómeno de las PAC tuvo un gran impacto en las estructuras sociales de la sociedad guatemalteca, especialmente en las áreas rurales con predominancia de población indígena. ${ }^{11}$

Asimismo, la Declaración de los derechos humanos debe ser acogida por las comisiones de la verdad en cuanto a los principios y derechos de dignidad, no discriminación,

11 Comisión Interamericana de Derechos Humanos, "Informe anual de la Comisión interamericana de derechos humanos 2000", https://www.cidh.oas.org/annualrep/2000sp/capituloiii/fondo/Guatemala10.626a.htm (acceso noviembre 5, 2021). 
vida, libertad, seguridad, no tratos crueles, inhumanos y degradantes, no injerencias arbitrarias, libre circulación, y libertad de opinión y pensamiento.

Por último, los Convenios de Ginebra de 1949 (DIH) y sus Protocolos Adicionales de 1977 abarcan los asuntos relativos a la protección de las personas y las víctimas en el marco de los conflictos armados. El DIH "prevé protección general a los niños, como personas que no participan en las hostilidades, y la protección especial, como personas particularmente vulnerables. Por lo demás, se protege también a los niños que participan en las hostilidades". ${ }^{12}$ De acuerdo con el IV Convenio, los NNAJ pertenecen a la categoría de personas protegidas como civiles en tiempos de guerra y no deben ser objeto de violencia que atente contra su vida, dignidad o persona. En el Protocolo I, artículos 8, 70, 77 y 88, y en el Protocolo II, artículo 4 , se los reconoce como sujetos de especial protección. Con respecto a los NNAJ y sus familias, el Protocolo I, artículo 74, dispone que debe hacerse lo posible para facilitar su reunificación tras separarse por causa del conflicto; el artículo 76 hace referencia a las mujeres en condición de embarazo o con niños muy pequeños e instituye que se debe evitar dictaminar la pena de muerte y que debe priorizarse la permanencia de los menores de edad con ellas. En el IV Convenio, artículo 24, el DIH protege también los valores morales, la religión, la cultura y las tradiciones con los que los NNAJ han sido educados, de manera que, en caso de desplazamiento u orfandad, deberá procurarse que puedan seguir desarrollándose en un entorno similar y con personas de su misma tradición cultural, lo cual se ve claramente vulnerada en eventos de secuestro y robo de identidad.

El Protocolo II, artículo 6, indica que no podrá dictaminarse pena de muerte a una persona menor de 18 años; por último, los Protocolos I y II prohíben el reclutamiento de menores de 15 años. En concordancia con estas disposiciones, los Estados parte se comprometen a adoptar las medidas para proteger a NNAJ afectados por el conflicto y a "tomar las medidas apropiadas para que los niños víctimas de la tortura, de conflictos armados, de abandono, de malos tratos o de explotación reciban un tratamiento apropiado, que asegure su recuperación y reintegración social". ${ }^{13}$

12 Comité Internacional de la Cruz Roja [CICR], "La protección a los niños en el derecho internacional humanitario", https://www.icrc.org/es/doc/resources/documents/misc/5tdll6.htm (acceso noviembre 5, 2021).

13 Unicef, Convención sobre los derechos del niño (Madrid: Autor, 1989), 26. 
Como se mencionó, la CEH de Guatemala dedica un capítulo de veintiún páginas al tema de la niñez y las diversas formas en las que fueron vulnerados sus derechos en el marco del conflicto armado interno que vivió el país. De acuerdo con lo consignado en el informe:

Durante el enfrentamiento armado interno uno de los sectores que fue profundamente afectado por la violencia fue la niñez. En su afán de desatar el terror en la población, el Estado generalizó la violencia en las áreas de conflicto, ocasionando la muerte de la población de modo indiscriminado. Miles de niños fueron objeto de violaciones de sus derechos humanos en un contexto de violencia que rebasa la imaginación más poderosa. ${ }^{14}$

En cuanto a Argentina, pese a que solo se abordó el tema de las desapariciones y a que la CDN aún no se había promulgado, se otorga un énfasis particular a NNAJ en el proceso de reconstrucción de la verdad; al respecto, en comparación con otras Comisiones de la Verdad, Bácares afirma que "a excepción de Argentina, donde se investigó el rapto de NNAJ por la dictadura militar, la infancia en un gran formato y con todas sus aristas quedaría relegada a un segundo renglón en las iniciativas sucesivas". ${ }^{15}$ Cabe recalcar que la CDN reconoce el derecho de NNAJ a preservar su identidad, lo que legitimaría aún más la reivindicación de las víctimas en Argentina en cuanto a la búsqueda de hijos y nietos sustraídos de sus padres y desaparecidos. De acuerdo con la CDN: "Es obligación del Estado proteger y, si es necesario, restablecer la identidad del niño, si éste hubiera sido privado en parte o en todo de la misma (nombre, nacionalidad y vínculos familiares)" ${ }^{16}$

Resulta imposible no mencionar la labor emprendida por Abuelas de la Plaza de Mayo, una organización no gubernamental (ONG) conformada en 1977, que tiene la finalidad de encontrar y restituir a sus verdaderas familias a los niños desparecidos (ahora adultos) durante la dictadura militar. Desde 1978 hasta 2021, las Abuelas han recuperado 130 nietos. De acuerdo con esta Organización:

En la ESMA, Campo de Mayo, Pozo de Banfield y otros centros de detención de la dictadura, funcionaron verdaderas maternidades clandestinas, incluso

14 República de Guatemala, Comisión para el Esclarecimiento Histórico, Guatemala, 58.

15 Camilo Bácares, "El protagonismo de la infancia en las Comisiones de la Verdad: desafíos y retos para el posconflicto en Colombia", Ciencia Política 14, núm. 27 (2019): 26, https://dialnet.unirioja.es/servlet/ articulo?codigo=7017246 (acceso noviembre 5, 2021).

16 Unicef, Convención, 10. 
con listas de matrimonios en "espera" de un nacimiento, y unos 500 hijos de desaparecidos fueron apropiados como "botín de guerra" por las fuerzas de represión. Algunos niños fueron entregados directamente a familias de militares, otros abandonados en institutos como NN, otros vendidos. En todos los casos les anularon su identidad y los privaron de vivir con sus legítimas familias, de sus derechos y de su libertad. ${ }^{17}$

Esta forma de robo de identidad se presentó también en Guatemala, como se expondrá, como una de las múltiples violencias a las que fueron sometidos NNAJ en el marco del conflicto armado, todas ellas documentadas en el informe Memoria del silencio. Así lo indica en informe REMHI:

Los niños y niñas están presentes en la mayor parte de los testimonios. Ya sea como víctimas indirectas de la violencia en contra de sus familiares, como testigos de muchos hechos traumáticos o sufriendo directamente sus propias experiencias de violencia y muerte, constituyen un grupo social muy afectado por la violencia y la represión política. ${ }^{18}$

\section{Metodología}

La investigación realizada es de tipo cualitativo y se enmarca en el análisis documental con enfoque hermenéutico, desde una perspectiva comprensiva-explicativa, pues tiene en consideración el carácter de los autores. ${ }^{19}$ Busca reproducir de manera creativa el pasado e indagar sobre la producción de verdad; privilegia el análisis comparativo y apunta a dilucidar la comprensión y el abordaje de la niñez en dos momentos históricos y contextos disímiles, en el marco de la figura Comisión de la Verdad. Los textos o informes producidos en estos escenarios de violencias extremas, que además tienen la finalidad específica de dar a conocer "la verdad", y la responsabilidad expresa de ofrecer recomendaciones para la memoria histórica, la reivindicación de las víctimas, el reconocimiento de los ofensores y las garantías de

17 Abuelas Plaza de Mayo, "Historia", https://www.abuelas.org.ar/abuelas/historia-9 (acceso abril 11, 2020).

18 República de Guatemala, Recuperación de la Memoria Histórica (REMHI), "Informe REMHI: Proyecto interdiocesano de recuperación de la memoria histórica (REMHI)", http://www.derechoshumanos.net/ lesahumanidad/informes/guatemala/informeREMHI-Tomol.htm (acceso noviembre 5, 2021).

19 En este caso quienes conformaron las Comisiones de la Verdad. Al respecto es importante recordar, por ejemplo, la participación de Ernesto Sábato en la Comisión de la Verdad de Argentina y en la construcción del informe Nunca más, lo que, sin duda, determina la forma en la que recibe la información, en términos de reconocimiento, legitimidad y aceptación. Este informe se convirtió en el libro más editado por las publicaciones argentinas. República de Argentina, Comisión Nacional sobre la Desaparición de Personas, El nunca más y los crímenes de la dictadura (Buenos Aires: Ministerio de Cultura, 1984). 
no repetición de actos y situaciones indeseadas y condenables, son imprescindibles para la aproximación y comprensión de fenómenos que se muestran superados, pero mantienen su vigencia en sociedades con heridas abiertas y con preguntas por responder.

Cuando se analiza concretamente un texto, se entiende que éste tiene un autor, con su propia historia de vida, con su contexto histórico que lo condiciona, con la situación en que ha vivido, se ha desarrollado, ha crecido, se ha constituido. Este análisis que se aplica a la existencia del autor del texto es aplicable a su vez al texto mismo, a la obra que se deja para la posteridad y que asume personalidad propia. El interés histórico de las obras transmitidas no se orienta sólo hacia los fenómenos históricos, sino también al efecto de los mismos en la historia. ${ }^{20}$

Se recurrió a los informes resultantes de las Comisiones de la Verdad en Argentina y Guatemala; textos académicos producidos alrededor de la temática particular (niñez y Comisiones de la Verdad); normativa internacional que debería considerarse en los procesos de verdad y memoria histórica; artículos de prensa, y pronunciamientos de organismos nacionales e internacionales. En torno a las categorías niñez y Comisiones de la Verdad, se identificaron subcategorías emergentes que fueron relacionadas entre sí, para identificar aspectos comunes y diferenciales entre los casos estudiados.

\section{Resultados}

\subsection{Prácticas sistemáticas de vulneración a los derechos humanos}

Las violaciones a los derechos humanos de NNAJ en los dos casos estudiados fueron documentadas en los informes, con mayor profundidad y detalle en el de Guatemala; en él se describieron y denunciaron verdaderos actos de sevicia y desprecio por la humanidad. En el de Argentina, por su parte, se hizo énfasis en el secuestro, el robo de identidad y la desaparición, en concordancia con el objeto de investigación de la Comisión.

20 Morella Arráez, Josefina Calles y Liuval Moreno de Tovar, "La hermeneútica: una actividad interpretativa", Sapiens 7, núm. 2 (diciembre 2006): 180, https://www.redalyc.org/pdf/410/41070212.pdf (acceso noviembre $5,2021)$. 


\subsubsection{Guatemala}

Se registraron casos de tortura, desaparición forzada, violencia sexual, privación de la libertad y ejecución arbitraria contra NNAJ. De acuerdo con las cifras del informe, el $18 \%$ del total de violaciones de los derechos humanos correspondió a agresiones contra NNAJ, es decir, 4249 de 23313 casos. No todos los eventos derivaron en muerte, pero se resaltaron las afectaciones a la integridad física y mental, así como el abandono por parte de sus familias. ${ }^{21}$ El informe REMHI señala:

Hay bebés que están acostados bajo los palos, en todas partes murieron, hay bebés que están colgados en las ramas de los árboles, es parecido a como les hacen cuando están en casa que les amarran con un trapo, así están colgados de las ramas de los árboles, y los bebés están vivos, pero ya no los puedes recoger, dónde los vas a dejar si no sabes dónde está su mamá". 22

Otros delitos recurrentes fueron la explotación, en forma de servidumbre en las casas de sus apropiadores; la privación de derechos culturales y colectivos, y la estrategia contrainsurgente de reclutamiento forzado para el fortalecimiento de las filas de las PAC. El informe de la CEH afirmó que por lo menos 20000 menores de 15 años fueron objeto de esta práctica, obligados a cumplir diferentes roles (rastreo, aprovisionamiento, vigilancia, operativos militares), privados de su vida cultural y expuestos a riesgos mayores.

La mera presencia de las PAC como estructuras armadas permanentes en muchas comunidades, ha tenido su influencia en los niños. Desde el miedo a las agresiones o la muerte, hasta la normalización de la violencia, la convivencia en un ambiente militarizado influye en la infancia con sus patrones de socialización bélica. Además, especialmente en los primeros años de las PAC, se describen casos de participación de menores y cómo ésta era una norma habitual en muchas comunidades. También se han dado numerosos casos de reclutamiento forzoso de menores por parte del Ejército durante prácticamente la totalidad del conflicto armado. ${ }^{23}$

\footnotetext{
21 Estas situaciones eran muy frecuentes, pues los niños y niñas pequeños suponían un riesgo para que los padres fueran descubiertos: el desplazamiento se hacía más lento y difícil, hacían ruido con sus llantos y gritos, dependían absolutamente del cuidado de los adultos.

22 República de Guatemala, REMHI, "Informe REMHI".

23 República de Guatemala, REMHI, "Informe REMHI".
} 
También fueron reportados casos de NNAJ vinculados a la guerrilla, en ocasiones como una forma de proteger sus vidas después de perder a sus familias en masacres orquestadas por el Estado o durante los operativos de tierra arrasada. Algunos de ellos fueron privados de su libertad, por considerarse implicados en asuntos políticos, porque se encontraban con sus padres cuando estos fueron apresados, y como estrategia para que sus padres fueran a buscarlos y así poder detenerlos a ellos. De acuerdo con los testimonios, los NNAJ no recibieron un tratamiento especial por su edad.

Todas estas prácticas fueron bastante detalladas y documentadas en el informe de la $\mathrm{CEH}$, pero tal vez la que más conmoción provocó fue la práctica de las masacres, muy extendida durante el conflicto:

La mitad de los casos de masacres registrados relatan asesinatos colectivos de niños y niñas. En este carácter indiscriminado de la violencia de las masacres, las descripciones de cómo murieron los niños incluyen frecuentes atrocidades (calcinamiento, lesiones por machete y descuartizamientos, y sobre todo traumatismos severos en la cabeza). Muchas menores fueron violadas durante masacres o capturas. En menor medida se recogen muertes de niños por acciones indiscriminadas de disparos o ametrallamientos de comunidades. Esto muestra un carácter directo de agresión intencional, congruente con el trato que sufrieron globalmente las comunidades en esas situaciones. ${ }^{24}$

Adicional a ello, los NNAJ víctimas de estos asesinatos masivos fueron los menos identificados por las personas que dieron testimonios, pues no eran reconocidos por sus comunidades, como sí lo eran los adultos. ${ }^{25}$

Otra consecuencia del conflicto fue la pérdida de la infancia, es decir, la obligación de asumir roles y responsabilidades de adultos, relacionadas, por ejemplo, con el cuidado de hermanos menores o con la necesidad de trabajar para garantizar la propia supervivencia, muchas veces con remuneraciones bajas o sin ella.

Muchos NNAJ fueron separados de sus familias y alejados de sus poblaciones, con lo que se vulneraron, entre otros, sus derechos culturales y tradiciones; algunos fueron regalados en otros pueblos y utilizados como sirvientes en casas de familia,

24 República de Guatemala, REMHI, "Informe REMHI".

25 Patrick Ball, Paul Kobrac y Herbert Spirer, Violencia institucional en Guatemala, 1960 a 1996: una reflexión cuantitativa (Nueva York: American Association for the Advancement of Science, 1999), 96. 
mientras que otros fueron ubicados en instituciones u hogares especiales. Por último, se reportó que debieron presenciar masacres contra sus familias y comunidades, lo que ocasionó una serie de afectaciones de difícil conciliación.

\subsubsection{Argentina}

El informe Nunca más recogió casos en los que los niños fueron institucionalizados y puestos en adopción, "privados de su identidad para que sus familiares no pudieran reconocerlos, y recluidos en orfanatos; algunos niños se vieron marginados de toda vida social y familiar". ${ }^{26}$ Además, denuncia graves afectaciones psicológicas y traumas, pues fueron obligados a presenciar hechos de violencia contra sus familiares, entre los que se reportan tortura, violencia sexual y asesinato.

En total, se registraron casi 250 jóvenes entre 13 y 18 años que desparecieron después de haber sido secuestrados en sus casas, en la vía pública o a la salida del colegio. Hoy en día, no se tiene conocimiento de su paradero. Como particularidad, el informe incluyó el caso de un niño que nació con graves afectaciones físicas y de salud, debido a que su madre, en estado de gestación, fue sometida a violencia sexual y física.

\subsection{El exterminio de las identidades indeseadas}

El plan del Ejército era dejar sin semillas. Aunque sea un patojito de un año, de dos años, todos son malas semillas, así cuenta. Así es su plan del Ejército. Eso es lo que yo he visto. ${ }^{27}$

Tanto en Argentina como en Guatemala es posible identificar que las violencias dirigidas a las víctimas por parte del Estado y de sus fuerzas represoras tienen un marcado énfasis no solo en el exterminio físico de quien se configura como enemigo interno, sino en el exterminio de su progenie.

\subsubsection{Guatemala}

Unos de los aspectos más denunciados por la CEH son el genocidio y la victimización del pueblo maya durante el conflicto, una muestra del modo de actuar racista y con herencia colonial empleado por el Estado, en su pretendida lucha antisubversiva.

26 República de Argentina, Comisión Nacional sobre la Desaparición de Personas, Nunca más.

27 República de Guatemala, REMHI, "Informe REMHI". 
Los NNAJ aparecieron en este campo como la semilla, como la posibilidad de supervivencia y conservación de este pueblo, lo que los convirtió en blanco de ataques, humillaciones, actos de crueldad y violencias extremas.

Los actos de violencia basada en género (VBG) y el mensaje simbólico que de allí se desprende dan cuenta de una política de exterminio que no respetó género, edad o condición de las víctimas. Una de las prácticas sistemáticas más crueles, documentada en el informe, fue abrir el vientre de las mujeres embarazadas, asesinarlas y privar también de la vida a los nonatos, quienes previamente eran empalados, quemados, reventados contra piedras o árboles, o destajados. Muchos de estos niños y niñas no aparecen en las estadísticas, porque no tenían nombre.

Por lo general, este tipo de acciones se produjeron en áreas rurales de población indígena, durante el período más alto de la violencia, en el marco de masacres y operaciones de tierra arrasada. El efecto directo de las matanzas de nonatos consistió en impedir nacimientos dentro del grupo indígena. El ensañamiento con el que se realizaron produjo también un efecto simbólico. Para el pueblo maya, las matanzas de nonatos tenían el mensaje cultural de matar la semilla, la raíz, afectando las posibilidades de la continuidad biológica de los colectivos indígenas. ${ }^{28}$

A las muertes de nonatos y de recién nacidos se sumaron las ejecuciones arbitrarias, muertes por desaparición y muertes por desplazamiento; en este último caso, los NNAJ fueron sometidos a jornadas extenuantes y aterradoras, privados de alimento, agua y resguardo, y expuestos a múltiples enfermedades que derivaron, en varias oportunidades, en la muerte. De acuerdo con el informe de Unicef sobre infancia y Comisiones de la Verdad, el 60 \% de las personas que murieron en el marco del desplazamiento forzado tenía menos de 18 años. ${ }^{29}$ Se comprende, entonces, que la muerte de NNAJ no correspondió a hechos casuales o a los excesos del conflicto, sino que ocurrió con una intencionalidad clara de exterminio físico y cultural.

Al respecto, en un informe emitido por la Asamblea General de las Naciones Unidas sobre las afectaciones de los NNAJ en conflictos armados se indica que quienes se ven forzados a huir se exponen a otros graves peligros y amenazas como:

28 República de Guatemala, Comisión para el Esclarecimiento Histórico, Guatemala, 61.

29 Unicef, Children, 42. 
[...] ataques repentinos, bombardeos, francotiradores y minas terrestres y a menudo deben caminar muchos días con cantidades limitadas de agua y alimentos. En esas circunstancias, los niños que están gravemente desnutridos son susceptibles de contraer enfermedades y son los primeros en morir. ${ }^{30}$

Esta situación concuerda con lo relatado en los informes de Guatemala respecto a los casos de desplazamiento forzado tanto de NNAJ con sus familias como de menores no acompañados.

El período comprendido entre 1982 y 1983 se ha denominado "el holocausto silencioso" y se caracterizó por ser el más violento de los 36 años que duró el conflicto armado en Guatemala. Se reconoce allí la práctica de genocidio con el exterminio de aproximadamente 440 comunidades maya y el ataque a más de $600 .^{31}$

Muchos niños fueron arrebatados del seno de su familia para ser ubicados en los hogares de sus victimarios o en familias ajenas a las suyas, con lo que se desconoció su procedencia familiar o las circunstancias que los llevaron a estar allí. De acuerdo con la CEH, "se puede inferir que cuando a los niños se les sacó de sus comunidades fueron entregados a familias o instituciones para que se hicieran cargo de ellos". ${ }^{32}$

\subsubsection{Argentina}

De acuerdo con el informe Nunca más, cuando los secuestros de padres o madres ocurrían en presencia de los niños, los represores procedieron de seis maneras: dejarlos con vecinos hasta que llegara algún familiar; trasladarlos a "Institutos de Menores, que los entregaban a familiares o los cedían en adopción"; ${ }^{33}$ secuestrarlos y darlos en adopción a algún represor; entregarlos a familiares; dejarlos a su suerte en su domicilio, o llevarlos al Centro Clandestino de Detención al que llevaban a sus padres, para ser torturados o presenciar la tortura de sus padres. Muchos de ellos permanecen desaparecidos.

30 Graça Machel, Repercusiones de los conflictos armados sobre los niños (Nueva York: Organización de las Naciones Unidas, 1996), 25.

31 Centro de Justicia y Rendición de Cuentas, "El caso de genocidio en Guatemala", https://cja.org/espanol-9/ casos-3/el-caso-de-genocidio-en-guatemala/el-caso-de-genocidio-en-guatemala-2/ (acceso noviembre 5 , 2021)

32 República de Guatemala, Comisión para el Esclarecimiento Histórico, Guatemala, 73.

33 República de Argentina, Comisión Nacional sobre la Desaparición de Personas, Nunca más. 
Los represores que arrancaron a los niños desaparecidos de sus casas o de sus madres en el momento del parto, decidieron de la vida de aquellas criaturas con la misma frialdad de quien dispone de un botín de guerra. Despojados de su identidad y arrebatados a sus familiares, los niños desaparecidos constituyen y constituirán por largo tiempo una profunda herida abierta en nuestra sociedad. En ellos se ha golpeado a lo indefenso, lo vulnerable, lo inocente y se ha dado forma a una nueva modalidad de tormento. ${ }^{34}$

Uno de los apartados del informe hace referencia a las mujeres embarazadas detenidas y a la desaparición de sus hijos, así como a la desaparición de NNAJ que fueron detenidos con sus padres o madres y de quienes no volvió a tenerse noticia. Al respecto, se afirmó que "cuando un niño es arrancado de su familia legítima para insertarlo en otro medio familiar elegido según una concepción ideológica de 'lo que conviene a su salvación', se está cometiendo una pérfida usurpación de roles". ${ }^{35}$

Otro apartado alude al tema de los niños nacidos en cautiverio. Sus madres debieron dar a luz en condiciones muy difíciles, a veces, asistidas por un médico ginecólogo, un dermatólogo y un enfermero o por otras mujeres. Según el informe, había listas de matrimonios dispuestos a adoptar a estos bebés, que fueron registrados como NN, de quienes no se volvió a saber nada, tal como ocurrió con sus madres. El caso más escandaloso ha sido el del hospital Campo de Mayo, al que ingresaban mujeres detenidas en condición de embarazo que no eran registradas y permanecían con sus ojos vendados y custodiadas; en la mayoría de los casos eran sometidas a cesáreas para precipitar los partos y eran separadas de sus hijos inmediatamente después del alumbramiento.

\subsection{La búsqueda: ¿encontrarlos u olvidarlos?}

\subsubsection{Guatemala}

Las recomendaciones específicas de la CEH en Guatemala sobre NNAJ desaparecidos, adoptados o separados ilegalmente de sus familias son:

- La creación de la Comisión nacional de búsqueda de niños desaparecidos, conformada por organismos nacionales (Procuraduría de Derechos Humanos y

34 República de Argentina, Comisión Nacional sobre la Desaparición de Personas, Nunca más.
35 República de Argentina, Comisión Nacional sobre la Desaparición de Personas, Nunca más. 
ONG de derechos humanos y de la niñez) e internacionales (Unicef, CICR y las ONG internacionales especializadas en niñez).

- La promulgación de medidas legislativas que favorezcan el acceso a la información sobre identidad, edad, lugar de origen, revisión de los procesos de adopción, localización y nombre actual.

- La implementación de una campaña nacional de búsqueda que vincule a los medios de comunicación.

Hasta la fecha, dichas recomendaciones no han sido implementadas de manera efectiva:

[...] el Comité de los Derechos del Niño les expresaría a los representantes del Estado guatemalteco, en respuesta a su informe obligatorio a este ente evaluador de la aplicación de la CDN, su preocupación por la abulia política imperante para resolver la situación de los NNAJ desaparecidos durante el conflicto armado, con todo y la existencia de fallos judiciales provenientes de la Corte Interamericana de Derechos Humanos que reclamaban la reparación a sus familias. ${ }^{36}$

El caso de Guatemala es tan complejo y los resultados tan escasos, que hoy en día se siguen discutiendo sus excesos y la necesidad de verdad y justicia. Al respecto, el diario El Espectador, emitió una nota sobre los niños robados en Guatemala durante la época del conflicto e introdujo un aspecto del que poco se ha hablado: el negocio de las adopciones, para el que se crearon verdaderas redes de secuestro y tráfico. De acuerdo con el artículo, "miles de niños fueron robados, secuestrados o dados en adopción en un lucrativo negocio que dejó millones de dólares y centenares de familias destruidas". ${ }^{37}$ Buena parte de ellos, ahora adultos, continúa en la búsqueda de sus familias de origen.

Bácares, "El protagonismo", 36.

37 Redacción Internacional, "El incierto destino de miles de niños durante la guerra en Guatemala", El Espectador, Sec. América, 19 de febrero de 2020, https://www.elespectador.com/noticias/el-mundo/ el-incierto-destino-de-miles-de-ninos-durante-la-guerra-en-guatemala-articulo-905242 


\subsubsection{Argentina}

El informe Nunca más estipuló la necesidad de "determinar la ubicación de niños sustraídos de la tutela de sus padres", ${ }^{38}$ misión abanderada y defendida por la Abuelas de Plaza de Mayo. Desde 1977, Las Abuelas convocan marchas semanales en la Plaza de Mayo, para reclamar la aparición de sus familiares. Al principio recibían testimonios por medio de llamadas telefónicas, notas escritas o charlas, en las que se reportaban mujeres con bebés que nunca estuvieron embarazadas o que no podían tener hijos propios; notificaciones sobre registros de nacimiento falsos o apariciones repentinas de bebés nuevos en los barrios. Todas estas informaciones fueron documentadas e investigadas por las Abuelas. Cuando era posible, se recurría al uso de las fotografías y rasgos físicos de los niños desaparecidos para intentar dar con su paradero; sin embargo, de los bebés nacidos en cautiverio no se contaba con ningún documento o conocimiento previo que favoreciera su búsqueda.

Por tal motivo, los esfuerzos de las Abuelas se extendieron internacionalmente a instituciones científicas de Suecia, Francia y Estados Unidos, para conseguir apoyos que permitieran la determinación de parentesco mediante pruebas de ADN, que ofrecen un 99,9 \% de veracidad. En 1982 se contactaron con la American Association for the Advancement of Science (Asociación Americana para el Avance de la Ciencia) y, desde ese momento, iniciaron los "trabajos destinados a la inclusión de los niños en las familias de las que faltan los progenitores [y] se busca la filiación con los abuelos (índice de 'abuelismo')". ${ }^{39}$ Uno de los métodos utilizados es el ADN mitocondrial (mtDNA), que comprueba la herencia transmitida por la madre, la cual varía muy poco de generación en generación; ello amplía la posibilidad de comprobar parentesco, incluso con muestras de un tío materno, por ejemplo Harvey-Blankenship, Pham y Shigekane. ${ }^{40}$

Después de adquirir renombre nacional e internacional se lograron también la creación del Banco nacional de datos genéticos de Argentina, que es un "archivo público y sistemático de material genético y muestras biológicas de familiares de personas secuestradas y desparecidas, durante la dictadura militar argentina", ${ }^{41}$ que custodia las muestras y que realiza los procesos genéticos de verificación de

República de Argentina, Comisión Nacional sobre la Desaparición de Personas, Nunca más.

República de Argentina, Comisión Nacional sobre la Desaparición de Personas, Nunca más.

40 Michele Harvey-Blankenship, Phuong Pham y Rachel Shigekane, Genetic Tracing, Disappeared Children and Justice (Florencia: Fondo de las Naciones Unidas para la Infancia [Unicef], 2010), 14.

${ }^{41}$ República de Argentina, "Banco nacional de datos genéticos", https://www.argentina.gob.ar/ciencia/bndg (acceso noviembre 5, 2021). 
identidad. Desde 1977 hasta la fecha, las Abuelas han ubicado a 130 nietos y continúan en su empeño de recuperarlos a todos. Muchas de ellas han fallecido, pero a su lucha se han unido muchas personas más, incluidos nietos restituidos.

\section{Conclusión}

Es preciso reconocer la influencia que ha ejercido la CDN en la inclusión de la niñez en las Comisiones de Verdad, así como las normas internacionales vigentes, pues otorga a los NNAJ un rol protagónico y los reconoce principalmente como víctimas; además, expone la necesidad de incluir sus voces y experiencias en la reconstrucción de la verdad, en los procesos de tránsito a la democracia y en los programas de reparación.

Si bien, para el caso de Argentina, la CDN no se había promulgado, resulta importante reconocer que se dedicó un apartado significativo de la investigación a NNAJ desaparecidos durante la dictadura. Cabe señalar que la búsqueda de estas personas se mantiene aún cuatro décadas después de los acontecimientos.

Guatemala, por su parte, destinó gran parte de su investigación al tema de la niñez y documentó de manera exhaustiva las violaciones a los derechos humanos y los excesos cometidos en el marco del conflicto armado contra ella. También aquí se hizo referencia puntual al tema de NNAJ desaparecidos y es justamente en este punto donde se encuentran los dos casos estudiados: el de los niños secuestrados a quienes se les robó su identidad.

A diferencia de Argentina, en Guatemala no se ha mostrado un verdadero interés o la voluntad política para dar con el paradero de dichos desaparecidos; situación duramente criticada por organismos internacionales como el Comité de los Derechos del Niño.

Otro elemento para resaltar es el uso y la instrumentalización de los NNAJ en escenarios de conflicto armado y político, quienes regularmente se conciben como "botín de guerra", son masacrados y eliminados, como un mensaje simbólico de erradicar la "semilla mala", y son vistos como un vehículo para castigar y torturar a sus padres, quienes no soportan el dolor de su pérdida, sea cual sea la forma que esta tome (desaparición, homicidio, apropiación). 
Entre las vulneraciones de derechos, comunes a ambos casos, se identificaron prácticas de tortura, recurrentes también en conflictos propios de otros países. Al respecto, Zamora y Barrera afirman:

[...] la tortura de NNA ocurre en distintos contextos, por ejemplo, en allanamientos por parte de la Policía, porque son percibidos como causantes de amenazas contra el orden público o la seguridad; cuando están encarcelados o en centros de detención; y cuando son percibidos como vinculados de cualquier forma a grupos subversivos, incluso por ser hijos de militantes. ${ }^{42}$

Sería pertinente estudiar la forma en la que en ambos países han implementado procesos de reparación de NNAJ víctimas y analizar su efectividad y sus resultados, así como la percepción sobre ellos como sujetos activos, partícipes de sus propios procesos de reparación, incidencia política y resiliencia. Al respecto, pueden resaltarse hechos documentados en los informes de Guatemala, en los que se reconocen posturas activas de quienes denunciaron los hechos de violencia ejercidos contra ellos y sus familias, o situaciones en las que reconstruyeron sus vidas, establecieron nuevos vínculos sociales o familiares, y sirvieron de apoyo a sus pares o a sus familiares. Para el caso de Argentina, debe mencionarse la postura de activismo político asumida por algunos de los nietos restituidos, quienes abanderan su propia causa y continúan con la búsqueda.

\section{Referencias}

Abuelas Plaza de Mayo. "Historia". https://www.abuelas.org.ar/abuelas/historia-9 (acceso abril 11, 2020).

Arráez, Morella, Josefina Calles y Liuval Moreno de Tovar. "La hermeneútica: una actividad interpretativa". Sapiens 7, núm. 2 (diciembre 2006): 171-181, https://www.redalyc. org/pdf/410/41070212.pdf (acceso noviembre 5, 2021).

Bácares, Camilo. "El protagonismo de la infancia en las Comisiones de la Verdad: desafíos y retos para el posconflicto en Colombia”. Ciencia Política 14, núm. 27 (2019): 19-46, https://dialnet.unirioja.es/servlet/articulo?codigo=7017246 (acceso noviembre 5, 2021).

Ball, Patrick, Paul Kobrac y Herbert Spirer. Violencia institucional en Guatemala, 1960 a 1996: una reflexión cuantitativa. Nueva York: American Association for the Advancement of Science, 1999.

42 Paola Alexandra Zamora Sierra y Lina Vanessa Barrera Jiménez, "Genealogía de la tortura en Colombia: una mirada desde los derechos humanos", Novum Jus 13, núm. 2 (2019): 135. 
Centro de Justicia y Rendición de Cuentas. "El caso de genocidio en Guatemala". https:// cja.org/espanol-9/casos-3/el-caso-de-genocidio-en-guatemala/el-caso-de-genocidioen-guatemala-2/ (acceso noviembre 5, 2021).

Centro Internacional para la Justicia Transicional [ICTJ]. "La comisión de la verdad y la reconciliación de Sierra Leona". https:/www.ictj.org/sites/default/files/subsites/ challenging-conventional-truth-commissions-peace/sierra_leone_es.html\#01/1 (acceso octubre 11, 2021).

Comisión de la Verdad para El Salvador. De la locura a la esperanza: la guerra de 12 años en El Salvador. San Salvador: Organización de las Naciones Unidas, 1993.

Comisión Interamericana de Derechos Humanos. "Informe anual de la Comisión interamericana de derechos humanos 2000". https://www.cidh.oas.org/annualrep/2000sp/capituloiii/ fondo/Guatemala10.626a.htm (acceso noviembre 5, 2021).

Comisión Interamericana de Derechos Humanos. "Justicia e inclusión social: los desafíos de la democracia en Guatemala”. http://www.cidh.org/countryrep/guatemala2003sp/ capitulo6.htm (acceso noviembre 5, 2021).

Comité Internacional de la Cruz Roja [CICR]. "La protección a los niños en el derecho internacional humanitario". https://www.icrc.org/es/doc/resources/documents/ misc/5tdll6.htm (acceso noviembre 5, 2021).

Harvey-Blankenship, Michele, Phuong Pham y Rachel Shigekane. Genetic Tracing, Disappeared Children and Justice. Florencia: Fondo de las Naciones Unidas para la Infancia [Unicef], 2010.

Hayner, Priscilla. "Comisiones de la verdad: resumen esquemático". International Review of the Red Cross, núm. 862 (2006): 1-18, https://www.icrc.org/es/doc/assets/files/other/ irrc_862_hayner.pdf (acceso noviembre 5, 2021).

Lefranc, Sandrine. “¿Cómo acabar con el desacuerdo? Las Comisiones de la Verdad y Reconciliación como lugar de reconstrucción disensual de la historia" en Memorias en conflicto, editado por J. B. Raynald Belay 193-233. Lima: Institut français d'études andines, Instituto de Estudios Peruanos, Embajada de Francia en el Perú, Red para el Desarrollo de las Ciencias Sociales en el Perú, 2004.

Machel, Graça. Repercusiones de los conflictos armados sobre los niños. Nueva York: Organización de las Naciones Unidas, 1996.

Millán Hernández, Juanita Andrea. "Comisiones de la Verdad y posibles aprendizajes para el caso colombiano”. Papel Político 20, núm. 2 (2015): 425-459, http://www.scielo. org.co/pdf/papel/v20n2/v20n2a06.pdf (acceso noviembre 5, 2021).

Redacción Internacional. "El incierto destino de miles de niños durante la guerra en Guatemala”. El Espectador, Sec. América, 19 de febrero de 2020, https:// www.elespectador.com/noticias/el-mundo/el-incierto-destino-de-miles-de-ninos -durante-la-guerra-en-guatemala-articulo-905242 
República Argentina, Comisión Nacional sobre la Desaparición de Personas. El nunca más y los crímenes de la dictadura. Buenos Aires: Ministerio de Cultura, 1984.

República Argentina. "Banco nacional de datos genéticos". https://www.argentina.gob.ar/ ciencia/bndg (acceso noviembre 5, 2021).

República Argentina. Ministerio de Relaciones Exteriores, Comercio Internacional y Culto. "Ayúdanos a encontrarte". https://www.cancilleria.gob.ar/es/encontrarte (acceso noviembre 5, 2021).

República de Chile, Comisión Nacional sobre Prisión Política y Tortura. Informe de la comisión nacional sobre prisión política y tortura. Santiago: Ministerio del Interior, 2004.

República de Guatemala, Comisión para el Esclarecimiento Histórico. Guatemala: memoria del silencio. Ciudad de Guatemala: Oficina de Servicios para Proyectos de las Naciones Unidas, 1999.

República de Guatemala, Recuperación de la Memoria Histórica (REMHI). "Informe REMHI: Proyecto interdiocesano de recuperación de la memoria histórica (REMHI)”. http://www. derechoshumanos.net/lesahumanidad/informes/guatemala/informeREMHI-Tomol. htm (acceso noviembre 5, 2021).

República del Perú, Comisión de la Verdad y la Reconciliación. "Informe final". https:// www.cverdad.org.pe/ifinal/ (acceso noviembre 5, 2021).

Unicef. Children and Truth Commissions. Florencia: Autor, 2010.

Unicef. Convención sobre los derechos del niño. Madrid: Autor, 1989.

Zamora Sierra, Paola Alexandra y Lina Vanessa Barrera Jiménez. "Genealogía de la tortura en Colombia: una mirada desde los derechos humanos". Novum Jus 13, núm. 2 (2019): 131-142. 